\title{
Parenting Stress and Related Factors of Parents in Self-Support Groups
}

\author{
Tae-Yeon Kim ${ }^{1}$, Na-Yeon Lee ${ }^{2}$ \\ Assistant Professor, Department of Child Studies, Jeonbuk National University \& \\ Researcher, Research Institute of Human Ecology, Jeonbuk National University Jeonju, Korea ${ }^{1}$ \\ Research Fellow, Gyeonggido Women \& Family Foundation, Suwon, Korea ${ }^{2}$ \\ 자조모임 참여 부모의 양육스트레스에 영향을 미치는 요인 \\ 김태연 ${ }^{1}$, 이나련 ${ }^{2}$ \\ 전북대학교 아동학과 조교수 ${ }^{1}$, 경기도여성가족재단 연구위원 ${ }^{2}$
}

\begin{abstract}
Objectives: The aim of this study was to evaluate the relationship between positive and negative effects of participating in self support group, attitudes towards self support group, parenting efficacy, and parenting stress among parents with preschool children by using structural equation modeling. Methods: The participants in this study were parents in Gyeonggido with at least one preschool child who participated in self-support groups. The number of participants was 495. The data were collected using an online survey, and structural equation modeling was employed to investigate significant factors related to parenting stress among parents in self-support groups. IBM SPSS 25.0 and AMOS 21.0 were used in this study to conduct statistical analysis.

Results: First, attitudes toward self-support group had no direct effect on parenting efficacy and parenting stress. Second, negative effects of self-support group had a significant direct effect on parenting stress. Parenting efficacy had also a direct effect on parenting stress. Finally, through parenting efficacy, the positive effects of self-support group had both direct and indirect effects on parenting stress. Parents who perceived the self-support group as having a higher level of positive impact reported higher parenting efficacy and they were less likely to experience parenting stress.

Conclusion: This study examined the mediation effect of parenting efficacy in relations between related factors of self support group(parents' attitudes and perceived effects) and parenting stress. Individuals' perceptions of the positive and negative effects of participating in self-support groups, rather than the circumstances of group activities, are highlighted in this study.
\end{abstract}

Keywords: preschool children, self support group, parenting stress, parenting efficacy

\section{Introduction}

자조모임(self support group)이란 공통의 어려움을 겪는 구성 원들 간 상호교환적인 도움을 추구하는 소집단 모임을 일컫 는다(Yalom, 1985). 자조모임은 동일한 경험이나 상황을 공유

Corresponding Author: Na-Yeon Lee, Research Fellow, Gyeonggido Women \& Family Foundation, Suwon, Korea, 1150, Gyeongsu-daero, Jangan-gu, Suwon-si, Gyeonggi-do, Korea

E-mail: nylee@gwff.kr
하는 사람들이 서로 도움과 이해를 통해 공통의 문제를 해결 하고, 자력으로 자신들의 권리를 실현하고자 하는 목적으로 구성된다. 이러한 자조모임의 종류 중 하나인 부모 자조모임 은 부모의 직장이나 자녀의 어린이집, 유치원, 학교 등을 중심 으로 이루어지며, 부모들의 자발적인 친목도모, 혹은 육아관

(C)The Korean Association of Child Studies

This is an Open Access article distributed under the terms of the Creative Commons Attribution Non-Commercial License (http:// creativecommons.org/licenses/by-nc/4.0) which permits unrestricted noncommercial use, distribution, and reproduction in any medium, provided the original work is properly cited. 
련 정보교류와 같은 목적을 지닌다(Mueller, Milian, \& Lopez, 2009; T.-Y., Kim, 2020).

부모 자조모임과 관련된 기존 연구들은 장애자녀를 둔 가 정이나 빈곤가정, 다문화가정과 같이 특별한 어려움을 가진 계 층을 중심으로 진행되어 왔다(T.-S. Seo \& Lee, 2017; Y. Lee \& Hwang, 2013). 자조모임을 통해 주변에서 쉽게 공감 받지 못하 는 어려움에 대해 이야기를 나누고, 서로 도울 수 있는 상대를 찾는 것이다. 그러나 최근에는 그런 특수한 사정이 없더라도, 영유아 자녀를 둔 많은 부모들이 사회적 변화로 인한 육아환경 에서의 어려움을 호소하고 이로 인해 자조모임에 대한 필요성 이 증가하고 있다(T.-Y., Kim, 2020). 핵가족화로 인한 육아부담 강화와 육아관련정보 부족의 문제(Y.-J. Yang \& Doh, 2019), 맞 벌이 상황에서 직업과 육아의 양립으로 인한 어려움(S.-J. Seo, $\mathrm{Kim}, \& \mathrm{Kim}, 2019)$, 블로그와 맘카페처럼 온라인에서 제공되 는 검증되지 않은 육아정보들로 인한 혼란(Y.-J. Chyung, 2020) 에 더해, 최근에는 코로나 19 상황으로 인한 유아교육기관과 시 간제보육지원 이용의 어려움까지 부모의 육아스트레스를 더 욱 증가시키고 있기 때문이다(S.-H, Kim, 2021).

한국의 부모들, 특히 맞벌이 가정의 어머니가 겪는 육아의 어려움으로 인한 높은 스트레스에 대해서는 이미 많은 연구 가 이루어졌다(I.-H. Lee, Choi, \& Song, 2013; S.-J. Seo, Kim, \& Kim, 2019). 부모의 양육스트레스는 부모 자신 뿐 아니라 자 녀의 행복, 그리고 가족체계에도 부정적 영향을 미친다(Oddi, Murdock, Vadnais, Bridgett, \& Gartstein, 2013). 예를 들어, 부 모의 높은 양육스트레스는 자녀의 낮은 사회성으로 이어지며 (Guranlnick, Nerville, Connor, \& Hammond, 2003), 자녀의 내 면/외면적 문제와도 높은 관련성을 보인다(Mäntymaa et al., 2012). 또한, 양육스트레스는 부모의 부정적 양육행동을 유발 하여 자녀의 발달에 직접적 영향을 미치고(Assel et al., 2002; Deater-Deckard, 1998), 이는 낮은 결혼만족도와 높은 부부갈 등으로 귀결된다(Lavee, Sharlin, \& Katz, 1996). 결국, 부모가 겪 는 양육스트레스는 부모 자신뿐 아니라 가족 전체의 존립 및 복지와 관련되는 중요한 요인이다.

영유아 부모들이 직면하는 스트레스가 증가함에 따라 다양 한 문제를 겪고 있는 부모들을 지원할 수 있는 다양한 정책도 만들어졌으며, 현재의 지원책들은 영유아의 보육'교육 지원, 육아비용 지원, 부모교육 제공 등에 집중되고 있다. 그러나 학 자들은 프로그램 중심으로 이루어지던 과거의 가족지원 정책 과 달리, 가족의 개별적 요구와 관심을 충족시키는 지원정책 이 중요한 것으로 보고하고 있다(J.-Y Park, Cho \& Kim 2004). 전문가 주도의 일방적인 부모교육 형태로 제공되는 공식적 지
원보다, 참가자들이 서로 자연스럽게 상호작용하며 각자의 요 구를 충족시킬 수 있는 비공식적 지원이 효과성과 지속성이 높다는 것이다(Y. Lee \& Hwang, 2013).

부모 자조모임은 이러한 비공식적 지원의 유용한 사례로써, 영유아 부모가 겪는 육아관련 어려움에 대한 효과적이고 지속 적인 대응책을 제공한다. 부모들은 비슷한 일상적 경험을 공유 하는 다른 부모들로부터 구체적 지원을 받기 원하며(McCabe, 2008), 친숙한 상대와의 정기적 모임에서 오는 사회적 연결감 과 지지를 통해 정신적, 신체적 건강에 긍정적 영향을 얻는다 (Thoits, 2011). 특히 자녀가 다니는 어린이집이나 학교를 중심 으로 구성된 학부모 모임은 참여부모들의 양육스트레스 경감, 자녀가치 변화 등에 긍정적 영향을 미친다(E.-J. Choi, 2013; Y. K. Lee \& Kim, 2016). 부모 자조모임의 대표적인 사례로 최근 육아종합지원센터와 건강가정.다문화가족지원센터를 중심으 로 활성화되고 있는 품앗이 육아공동체를 들 수 있다.

정부는 2017년 국정과제인 보육·양육에 대한 사회적 책임 강화를 실현하기 위해 제 3 차 중장기보육 기본계획을 발표하 였으며, 정책과제 주요 4 개 분야의 하나로 부모 양육지원 확 대를 선정하였다. 이를 위한 세부 추진과제로 부모의 양육역 량 강화를 위한 육아관련 정보 제공 계획과 가정양육 지원을 위한 육아종합지원센터의 서비스 확대 및 다양화 계획을 제 시하였고, 구체적인 실천방안으로써 지역 내 육아종합지원센 터 분소 확대와 영유아 부모 대상의 부모교육, 자조모임 지원 을 통한 양육지원 기능 활성화 방안을 모색해왔다(Ministry of health and welfare, 2017). 또한, 건강가정.다문화가족지원센터 는 가족돌봄지원사업의 일환으로 '육아품앗이'사업을 지속적 으로 운영하고 있으며 2013년 아이돌봄지원법 시행에 따라 이러한 육아품앗이의 활동공간으로 공동육아나눔터를 운영 하고 있다(N.-Y. Lee, 2017). 이를 벤치마킹하여 경기도, 전라도 를 포함한 여러 지자체에서도 자체적으로 공동육아나눔터를 운영하고 있다. 육아품앗이를 비롯한 공동육아모임에서는 같 은 지역, 이웃에 사는 사람끼리 자녀 돌봄과 양육 등의 상호호 혜적 교환이 이루어진다(Ministry of gender equality and family, 2020). 품앗이 육아는 참여자들의 높은 만족감과 장기적이고 지속적인 참여를 얻었으며, 양육효능감을 향상시키는 데 의미 있는 효과를 보였다(E.-J. Choi, 2013; N.-Y. Lim, 2014).

양육효능감은 Bandura (1977)의 자기효능감 이론을 양육 차원에 적용하여, 자신의 자녀양육 능력에 대한 부모의 믿음 을 의미하는 개념이다. 양육효능감은 자녀와 관련된 어려움에 대해 성공적으로 해결하고자 하는 동기를 부여하며(Jones $\&$ Prinz, 2005), 부모의 긍정적 양육행동을 이끌어낸다(I.-H. Lee, 


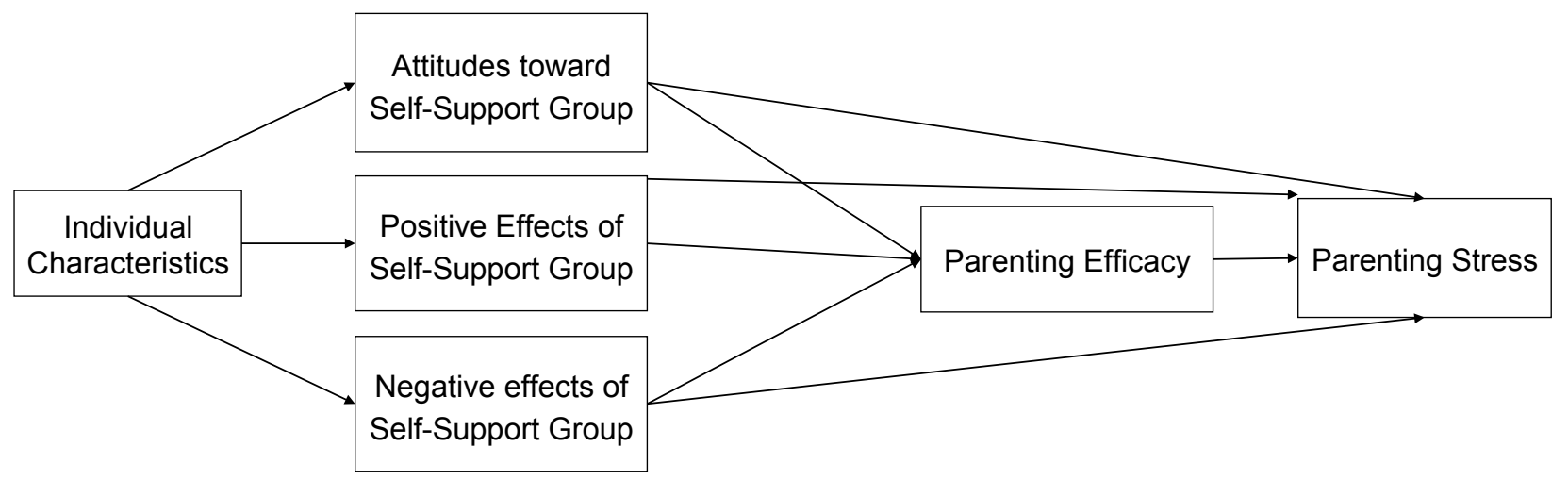

Figure 1. Conceptual Model

Choi, \& Song, 2013). 높은 양육효능감은 부모가 경험하게 되 는 다양한 스트레스 대처를 위한 효과적인 자원으로 기능하며 (Abidin, 1992), 양육스트레스 감소와도 밀접한 관계가 있는 것 으로 보고된다(Jackson \& Huang, 2000). 따라서 부모 자조모임 을 통해 향상된 양육효능감이 부모의 양육스트레스를 낮추는 데에 긍정적 영향을 미치리라 예상할 수 있다.

특정 모임이나 프로그램의 효과를 알아보고자 한 기존의 연구들은 참여 여부를 독립변인으로 삼아 집단 간 차이를 살 펴본 경우가 많았다(H.-M. Hwang, 2017; T.-Y. Kim, Jung, Yi, 2016). 그러나 프로그램 참여에 관한 질적 연구들은 단순한 참 여 여부뿐 아니라, 참여대상자의 연령이나 월소득 같은 개인 적 특성과 참여 동기, 적극성 수준, 본인의 만족도, 기대효과 등에 따라 프로그램에서 얻어지는 효과가 다름을 보고하고 있 다(C.-H. Seo, Park, Baek \& Kim, 2017; Y. Lee \& Hwang, 2013). 유사한 사례로 성인대상 상담/교육 프로그램의 효과에 대한 선행연구에서는 참여자의 개인적 특성이 프로그램에 대한 참 여도나 태도에 영향을 미침을 보고하고 있으며(Y.-N. Ko \& Lee, 2011), 본 연구의 주요변인인 양육효능감과 양육스트레 스 역시 부모의 연령과 가정의 소득수준으로 인해 직접적 영 향을 받는다(M.-J. Lee \& Kim, 2007; S.-H. Son \& Han, 2016). 선행연구(J.-Y. Ding \& Chi, 2017)에서도 외국인 어머니의 우 울감에 대한 자조모임 참여의 매개효과를 검증하는 과정에서 참여자의 성별과 교육수준, 가구소득을 통제변수로 사용하였 다. 따라서 참여대상자의 개인특성의 영향력을 통제하고, 자 조모임 참여부모들의 모임에 대한 태도, 긍정적/부정적 효과 에 대한 인식을 독립변인으로 하여 보다 세부적인 모임의 효 과를 살펴볼 필요가 있다.

지금까지 살펴본 바와 같이, 영유아 부모의 자조모임 참여 는 실질적이고 정서적인 지원을 통해 부모의 양육효능감을 높 이며, 궁극적으로는 양육스트레스를 낮추는 데 영향을 미칠
것으로 예상할 수 있다. 특히, 부모의 자조모임에 대한 주관 적 태도나 자조모임 참여 효과에 대한 인식을 중심으로 그 세 부적 효과가 달라질 것이다. 이에 본 연구에서는 부모의 자조 모임에 대한 태도, 자조모임 참여로 얻은 긍정적/부정적 효과, 양육효능감, 양육스트레스의 관계를 밝히기 위해 다음과 같은 연구문제와 와 연구모형 Figure 1을 설정하였다.

\section{연구문제 1}

부모 자조모임에 대한 태도, 자조모임의 긍정적 효과, 자조모 임의 부정적 효과, 양육효능감은 부모의 양육스트레스에 어 떠한 영향을 미치는가?

1-1. 부모의 개인변인, 부모 자조모임에 대한 태도, 자조모 임의 긍정적 효과, 자조모임의 부정적 효과, 양육효능감, 양육스트레스 간의 관계는 어떠한가?

1-2. 부모의 개인변인, 부모 자조모임에 대한 태도, 자조모 임의 긍정적 효과, 자조모임의 부정적 효과, 양육효능감은 부모의 양육스트레스에 어떠한 영향을 미치는가?

\section{Methods}

\section{연구대상}

본 연구의 대상은 경기도에 거주하는 취학전 영유아 자녀를 둔 부모로, 육아와 관련한 부모 자조모임에 참여한 경험이 있 는 성인 남녀이다. 참여자의 연령은 25세까지부터 54세까지 로, 평균 연령은 36.9세 $(S D=4.0)$ 였으며, 남자는 66명 $(13.3 \%)$, 여자는 429명(86.7\%)이었고, 양부모 가족이 458명(92.5\%), 
한부모 가족이 3 명 $(0.6 \%)$, 조부모와 동거하는 양부모 가족 이 31 명 $(6.3 \%)$, 조부모와 동거하는 한부모 가족이 3 명 $(0.6 \%)$ 이었다. 부모의 직업과 관련하여, 아버지의 직업군은 사무/회 계(152명, 30.7\%), 전기/전자(65명, $13.1 \%)$, 교육/연구(63명, $12.7 \%)$, 건설/기계/화학/운송(58명, $11.7 \%$ ) 순이었으며, 어머 니의 직업군은 주부(204명, $41.2 \%$ ), 교육/연구(120명, $24.2 \%$ ), 사무/회계(74명, $14.9 \%)$, 보건/의료(28명, $5.7 \%)$ 순이었다. 부 모학력에 관한 조사에서는 아버지(298명, 60.2\%)와 어머니 (294명, 59.4\%) 모두 대졸의 비율이 가장 높았다. 가구소득은 300 만 400만 원이 109 명(22.0\%), 400만 500만 원이 108명 (21.8\%), 500만 600 만 원이 81명(16.4\%) 순이었다.

\section{연구도구}

\section{부모 자조모임에 대한 태도}

참여하고 있는 자조모임 자체에 대한 부모의 태도를 측정하기 위하여 자조모임 운영에 대한 전반적인 평가 및 모임에 대한 만족 수준을 2 개의 문항으로 측정하였다. 본 척도는 사전에 이 루어진 자조모임 부모 대상 FGI의 결과를 토대로 구성되었으 며, 아동학과 유아교육학, 가족학 전문가 3 인의 안면타당도 검 증을 거쳤다. 문항별로 5점 Likert 척도로 측정되었으며, 점수 가 높을수록 자조모임 운영이 잘 되고 있다는 인식과 높은 만 족도를 의미한다. 본 연구에서 척도의 신뢰도 계수는 .76으로 양호하게 나타났다.

\section{부모 자조모임의 긍정적 효과}

자조모임의 긍정적 효과는 부모들이 자조모임에 참여하여 얻 었다고 느낀 효과 중 긍정적인 부분에 대한 질문이다. 위의 자 조모임에 대한 태도가 운영의 전반적인 부분에 대한 질문이라 면, 이 변인은 운영과 관계없이 본인이 모임을 통해 얻는 개인 적 효과에 관해 집중적으로 묻는 내용이다. 측정문항은 사전 에 이루어진 부모 FGI의 내용을 기반으로 구성하였으며, 구성 된 척도는 아동학, 유아교육학, 가족학 전문가 3 인의 감수를 받아 타당도를 검증하였다. 최초구성된 척도는 5 개 문항으로 이루어졌으나, 예비조사를 통해 내적합치도가 낮은 2 개 문항 을 삭제하여 최종 3 개 문항으로 결정되었다. 측정문항은 심리 적 지원, 정보지원, 자신감 향상에 관한 내용으로 구성되어 있 고, 5점 Likert 척도로 측정되었으며, 점수가 높을수록 자조모 임의 긍정적 효과에 대해 강하게 인식함을 의미한다. 본 연구
에서 척도의 신뢰도 계수는 .72로 양호하게 나타났다.

\section{부모 자조모임의 부정적 효과}

자조모임의 부정적 효과는 부모들이 자조모임에 참여하여 얻 었다고 느낀 효과 중 부정적인 부분에 대한 질문이다. 자조모 임의 긍정적 효과와 반대로, 이 변인은 본인이 모임을 통해 얻 는 개인적인 부정적 효과에 대해 묻는다. 사전 부모 FGI 내용 에 기반하여 측정문항을 구성하였으며, 구성된 척도는 아동 학, 유아교육학, 가족학 전문가 3 인의 감수를 받았다. 최초구 성된 척도는 5 개 문항으로 이루어졌으나, 예비조사를 통해 내 적합치도가 낮은 1 개 문항을 삭제하여 최종 4 개 문항으로 결 정되었다. 세부문항은 시간 소모, 금전적 소모, 다른 부모와의 비교, 다른 아이와의 비교에 관한 내용으로 구성되어 있고, 5 점 Likert 척도로 측정되었으며, 점수가 높을수록 자조모임의 부정적 효과에 대해 강하게 인식함을 의미한다. 본 연구에서 척도의 신뢰도 계수는 .69로 양호하게 나타났다.

\section{부모의 양육효능감}

부모의 양육효능감을 측정하기 위해 Choi와 Chung (2001)이 개발한 양육효능감 척도를 사용하였다. 이 척도는 전반적 양 육능력, 건강관리능력, 의사소통능력, 학습지도능력, 훈육능 력의 5 개 하위요인으로 이루어져 있으며, 점수가 높을수록 스 스로의 양육능력을 높게 평가함을 의미한다. 본 연구에서 하 위요인의 신뢰도 계수는 전반적 양육능력 .91, 건강관리능력 .86 , 의사소통능력 .89 , 학습지도능력 .82 , 훈육능력 .77 이었으 며, 전체 척도의 신뢰도 계수는 .97로 높게 나타났다.

\section{부모의 양육스트레스}

부모의 양육스트레스를 측정하기 위해 Abidin (1990)이 개발 한 양육스트레스 검사 (Parent Stress Index [PSI])의 한국어 번 역본을 신숙재 (1997)가 수정한 척도를 사용하였다. 이 척도 는 자녀와의 관계로 인한 스트레스, 자녀의 기질과 관련된 스 트레스, 학습기대와 관련된 스트레스의 3 개 하위요인으로 이 루어져 있으며, 점수가 높을수록 부모가 양육에서 스트레스를 많이 받고 있음을 의미한다. 본 연구에서 하위요인의 신뢰도 계수는 자녀와의 관계 관련 스트레스 .73, 자녀 기질 관련 스트 레스 .85, 학습기대 관련 스트레스. 78 이었으며, 전체 척도의 신뢰도 계수는 .87로 높게 나타났다. 
Table 1

Descriptive Statistics of Variables

$(N=495)$

\begin{tabular}{|c|c|c|c|c|}
\hline Variables & $M$ & $S D$ & Min & $\operatorname{Max}$ \\
\hline \multicolumn{5}{|l|}{$\begin{array}{l}\text { Attitudes toward } \\
\text { self-support group }\end{array}$} \\
\hline Satisfaction & 4.02 & .87 & 1.00 & 5.00 \\
\hline Emotional support & 3.91 & .95 & 1.00 & 5.00 \\
\hline Information & 3.76 & .93 & 1.00 & 5.00 \\
\hline Increasing confidence & 3.68 & .87 & 1.00 & 5.00 \\
\hline Waste of money & 2.81 & .99 & 1.00 & 5.00 \\
\hline $\begin{array}{l}\text { Comparison with other } \\
\text { parents }\end{array}$ & 2.64 & 1.12 & 1.00 & 5.00 \\
\hline $\begin{array}{l}\text { Comparison with other } \\
\text { child }\end{array}$ & 2.77 & 1.18 & 1.00 & 5.00 \\
\hline Parenting efficacy & 138.74 & 20.85 & 82.00 & 180.00 \\
\hline Parenting stress & 46.65 & 11.58 & 20.00 & 78.00 \\
\hline
\end{tabular}

Note. $N=495$.

\section{연구절차}

본연구의 자료는 경기도가족여성연구원의 부모 역량 강화를 위한 자조모임 활성화 방안 연구(Kim, T.-Y., 2020) 원자료를 재분석한 것으로, 자료 조사는 2020년 7월과 8월에 이루어졌 으며, 코로나 19 로 인해 대면조사가 어려운 상황을 감안하여 온라인 설문을 통해 시행하였다. 원활한 조사 진행을 위해 육 아종합지원센터와 건강가정.다문화가족지원센터에서 시행하 는 부모교육 프로그램, 육아지원 프로그램에 참여한 적이 있 는 부모들과 지역 맘카페에서 활동하고 있는 부모들에게 홍보 메시지를 보내 설문 참여자를 모집하였으며, 설문지의 마지막 질문까지 완료한 응답자에게 소정의 사례를 지급하였다. 설문 참여자는 설문 시작 전 조사의 목적, 조사결과의 사용 및 게시 에 대한 안내문을 읽었고, 정보 제공을 위한 자발적 참여 및 사 례 수령에 동의하였다. 이렇게 수합된 설문결과는 미완성 응 답지를 1 차적으로 제외하고, 완료된 설문 중 완료시간이 지나 치게 짧거나 답변의 편향성이 높은 부실응답지 67부를 제외
한 총 495부를 최종분석에 사용하였다.

\section{자료분석}

설문지 조사를 통해 얻어진 자료를 IBM SPSS 25.0 (IBM Co., Armonk, NY)과 IBM AMOS 21.0 (IBM Co., Armonk, NY)을 이 용하여 분석하고 부모자조모임에 대한 태도, 부모 자조모임의 긍정적 효과, 부모 자조모임의 부정적 효과, 양육효능감, 양육 스트레스 간의 관계를 나타내는 구조방정식 모형을 분석하였 다. 먼저 연구대상의 사회인구학적 배경을 파악하기 위해 빈 도와 백분율을 확인하였으며, 둘째, 연구모형 간 변인들의 양 상과 관계 파악을 위해 기술통계와 상관분석을 실시하였다. 셋째, 연구에서 사용된 척도의 신뢰성을 확인하기 위해 신뢰 도 분석을 시행하였다. 넷째, 구조방정식을 활용하여 연구모 형의 적합도 및 유의한 경로를 검증하였다 
Table 2

Summary of Exploratory Factor Analysis

\begin{tabular}{cccccc}
\hline$\chi^{2}$ & $d f$ & $p$ & NFI & CFI & RMSEA \\
\hline 50.64 & 17 & .00 & .96 & .97 & .06 \\
\hline
\end{tabular}

Table 3

Factor Loadings of Exploratory Factor Analysis

\begin{tabular}{|c|c|c|c|c|c|}
\hline Latent Variables & Measured Variables & $B$ & $\beta$ & S.E. & C.R. \\
\hline \multirow[t]{2}{*}{ Attitudes toward self support group } & Satisfaction & 1.00 & .87 & & \\
\hline & Overall evaluation of operating & .84 & .70 & .09 & 11.75 \\
\hline \multirow[t]{3}{*}{ Positive effects of self support group } & Emotional support & 1.00 & .83 & & \\
\hline & Information & .69 & .58 & .06 & 10.84 \\
\hline & Increasing confidence & .69 & .62 & .06 & 11.36 \\
\hline \multirow[t]{3}{*}{ Negative effects of self support group } & Waste of time & 1.00 & .50 & & \\
\hline & comparison with other parents & 1.79 & .93 & .17 & 10.78 \\
\hline & Comparison with other children & 2.04 & .90 & .20 & 10.46 \\
\hline
\end{tabular}

Table 4

Summary of Research Model Fit

\begin{tabular}{cccccc}
\hline$\chi^{2}$ & $d f$ & $p$ & NFI & CFI & RMSEA \\
\hline 78.36 & 41 & .00 & .95 & .98 & .04 \\
\hline
\end{tabular}

\section{Results}

\section{연구변인의 일반적 경향}

본 분석에 앞서 모델에 사용되는 측정변인의 기술통계를 시행 하여 평균 및 표준편차, 왜도 및 첨도를 확인하였고, 변인들 간 의 상관관계를 알아보기 위하여 Pearson 적률상관계수를 산출 하였다. Table 1과 같이, 자조모임에 대한 태도 평균은 3.83점 $(S D=.80)$, 자조모임에 대한 긍정적 효과 인식의 평균은 3.78 점 $(S D=.73)$, 자조모임의 부정적 효과 인식의 평균은 2.71점 $(S D=.85)$, 양육효능감의 평균은 138.74 점 $(S D=20.85)$, 양육 스트레스의 평균은 46.65 점 $(S D=11.58)$ 이었다. 각 측정변인 의 왜도 및 첨도의 절댓값은 1 이하로 정규성 가정을 만족시키 는 것으로 나타났다.

기초분석으로 실시한 주요변인 간의 상관관계 분석 결과, 양육스트레스는 자조모임에 대한 태도 $(r=-.18, p<.001)$, 자조 모임의 긍정적 효과 $(r=-.25, p<.001)$, 양육효능감 $(r=-.50, p<$ .001)과 유의한 부적 상관을 보였으며, 자조모임의 부정적 효 과 $(r=.15, p<.01)$ 와 유의한 정적 상관을 보이는 것으로 나타났 다. 즉, 자조모임에 대한 태도가 긍정적이고, 긍정적 효과를 많
이 체감하며, 양육효능감이 높을수록 양육스트레스가 낮았고, 자조모임의 부정적 효과를 많이 체감할수록 양육스트레스가 높았다. 반면, 양육효능감은 자조모임에 대한 태도 $(r=32, p<$ $.001)$, 자조모임의 긍정적 효과 $(r=.43, p<.001)$ 와 유의한 정적 상관을 보였으나, 자조모임의 부정적 효과와는 유의한 상관을 보이지 않았다 $(r=-.09, n s)$. 즉, 자조모임에 대한 태도가 긍정적 이고, 긍정적 효과를 많이 체감할수록 양육효능감이 높았다.

\section{양육스트레스에 영향을 미치는 요인}

\section{측정모형 분석}

잠재변인을 포함한 연구모형 분석하기에 앞서, 자조모임에 대 한 태도, 자조모임의 긍정적 효과 및 부정적 효과의 측정모형 검증을 위해 확인적 요인 분석을 실시하였다. 자조모임의 부 정적 효과의 측정변인 중 금전적 소모는 요인부하량이 .50이 하로 나타나 제거하였다. Table 2 와 같이 최종 측정모형의 적 합도는 타당한 것으로 나타났으며 각 잠재변인에 대한 측정변 인의 요인부하량은 Table 3 에 제시하였다.

위에 제시된 것처럼 측정모형의 적합도가 타당하며, 각 측 


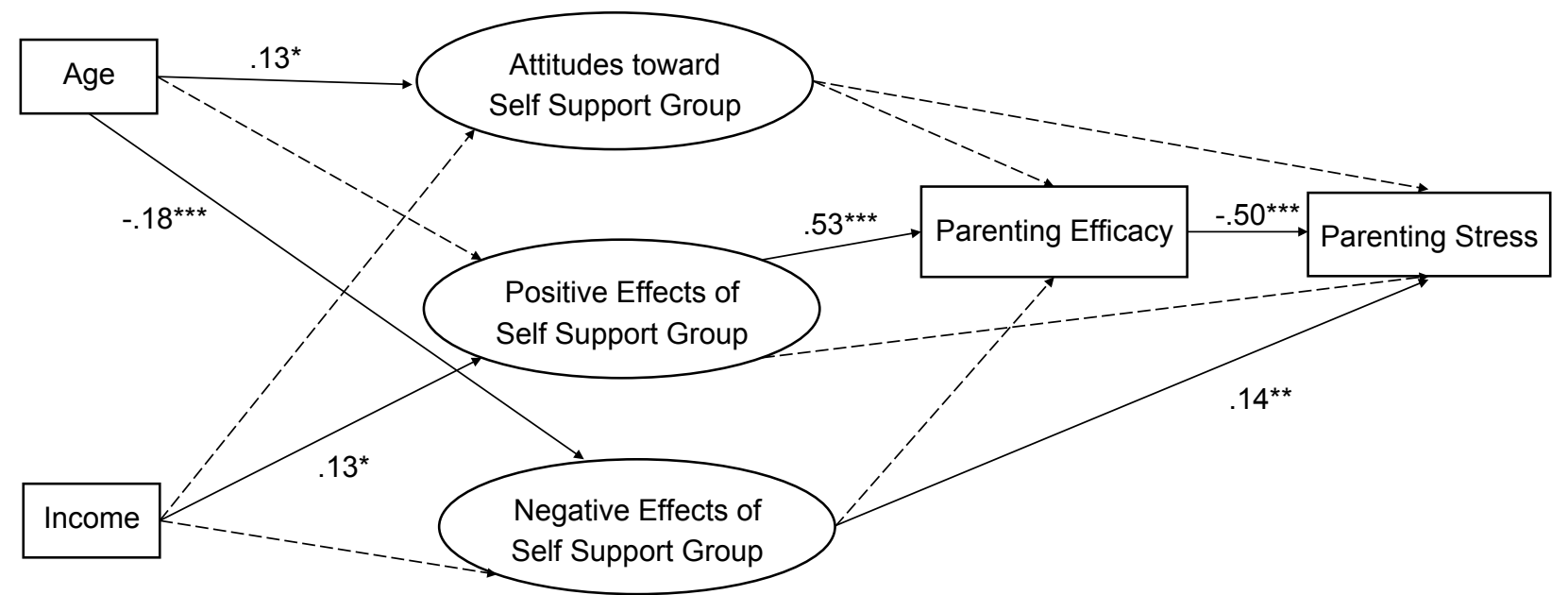

Figure 2. Standardized solutions for structural equation model. ${ }^{*} p<.05 .{ }^{* *} p<.01 .{ }^{* * *} p<.001$.

정변인의 잠재변인에 대한 요인부하량 역시 적합하여 연구모 형 분석을 실시하였다.

\section{연구모형 분석}

구조방정식 모형의 카이제곱 검증 결과가 유의하게 나타났으 나 표본크기를 고려하여 다른 적합도 지수를 살펴본 결과, $\mathrm{Ta}-$ ble 4와 같이 NFI, CFI가 .90을 넘는 수준이었고 RMSEA가 .04 로 좋은 적합도 기준인 .05보다 낮은 수준을 보여 모형의 적합 도는 좋은 것으로 나타났다.

양육스트레스 및 양육효능감, 자조모임에 대한 태도, 자조 모임의 긍정적, 부정적 효과 간의 관계를 살펴보기 위하여 변 인들간의 경로계수를 산출하였다. 개인변인인 연령과 수입을 먼저 살펴보면, 연령은 자조모임의 긍정적 효과에는 영향을 미치지 않았으나 자조모임의 부정적 효과 $(\beta=-.17, p<.001)$ 및 자조모임에 대한 태도 $(\beta=.13, p<.05)$ 에는 유의미한 영향 을 미치는 것으로 나타났다. 즉 연령이 증가할수록 자조모임 에 대한 부정적 효과 인식수준은 감소하고 자조모임에 대한 태도는 긍정적인 것으로 나타났다. 연령과 달리 수입은 자조 모임의 긍정적 효과 $(\beta=.13, p<.05)$ 에만 유의미한 영향을 미 치는 것으로 나타나 수입이 증가할수록 자조모임에 대한 긍정 적 효과 수준이 높아졌다.

연구모형에서 주요변인들의 직접효과 경로계수를 살펴보 면, 자조모임의 긍정적 효과는 양육효능감에 직접적인 영향을 미치는 것으로 나타났으며 $(\beta=.53, p<.001)$, 양육효능감은 양 육스트레스에 직접적인 영향을 미쳤다 $(\beta=-.50, p<.001)$. 즉,
자조모임에 대한 긍정적 효과 인식이 높을수록 양육효능감 수 준은 높게 나타났으며, 양육효능감 수준이 높을수록 양육스트 레스는 수준은 낮은 경향을 보였다. 자조모임의 부정적 효과 는 양육효능감에는 직접적인 영향을 미치지 않았으나, 양육스 트레스에는 직접적인 영향을 미치는 것으로 나타났다 $(\beta=.14$, $p<.01)$. 자조모임의 부정적 효과를 높게 인식할수록 부모가 인지하는 양육스트레스 수준은 높게 나타났다. 자조모임의 긍 정적 효과는 유의미하게 양육스트레스에 영향을 미치지는 않 았으나 양육효능감을 매개로 간접영향을 미치는 것으로 나타 났다. 즉 자조모임의 긍정적 효과에 대한 인식이 높을수록 양 육효능감이 높아지고 양육스트레스는 감소하는 경향을 보였 다. 이러한 결과를 모형으로 그려보면 Figure 2와 같다.

\section{Discussion}

본 연구는 영유아 부모 자조모임에 대한 태도와 자조모임에서 얻은 긍정적 효과, 부정적 효과가 양육스트레스에 미치는 영향 에 관하여 양육효능감을 매개로 살펴보고자 하였다. 기존 자조 모임에 관한 연구들이 장애, 다문화 등 특수집단 부모를 대상으 로 이루어진 데 반해, 본 연구는 영유아 자녀를 둔 부부들 역시 자조모임을 통해 지원과 지지를 얻고, 양육스트레스를 낮출 수 있음에 주목하였다. 또한, 단순히 모임 참여 여부가 아닌, 자조 모임 운영과 관련한 태도, 자조모임에서 얻는 긍정적/부정적 효 과에 대한 인식 등을 세부적으로 분류하여 각각이 양육효능감 과 양육 스트레스에 미치는 영향을 알아보고자 하였다. 이를 위 
해 경기도에 거주하는 취학전 영유아 자녀를 둔 부모로, 육아와 관련한 부모 자조모임에 참여한 경험이 있는 부모 총 495명의 설문조사 결과를 분석하여 구조방정식 모형을 구성하고 그 관 계성을 분석하였다. 그 결과, 다음과 같은 결론을 도출하였다.

첫째, 영유아 부모의 자조모임에 대한 전반적인 태도는 양육 효능감에 영향을 미치지 않았으나, 자조모임을 통해 얻은 긍정 적/부정적 효과는 양육효능감을 향상시키고 양육스트레스 감 소에도 영향을 미쳤다. 이는 자조모임의 원래 취지인 효능감 향 상과 스트레스 감소를 위해서는, 자조모임의 원활한 운영과 만 족도 향상 같은 표면적인 부분에 집중하기보다, 실질적으로 부 모들이 체감하는 긍정적/부정적 효과를 변화시키는 것이 중요 함을 의미한다. 부모들은 자조모임의 활성화나 운영에 다소 불 만이 있더라도, 본인이 얻는 긍정적 효과(정보 획득, 정서적지 지 등)가 충분하고, 부정적 효과(시간적 소모, 다른 부모/자녀와 의 비교 등)가 적다고 느낀다면, 양육효능감 향상과 양육스트 레스 감소에 도움을 받을 수 있다는 것이다. 자조모임에 참여하 는 부모들은 자조모임을 통해 자신들이 획득하게 되는 정보나 정서적 지지와 같이 실제 일상생활에서 양육에 도움이 되는 요 소들이 중요하다는 것을 보여준다. 온라인상에서 많은 육아모 임이 이루어지고 있는 것도 실제 양육에서 활용할 수 있는 다양 한 정보를 공유할 수 있다는 점에서 부모들의 참여가 많은 것 으로 볼 수 있다. 부모들의 적극적인 자조모임 활동을 지원하기 위해서는 자모모임에서 일상적 양육활동에 직접적으로 도움이 되는 요소를 가져가는 것이 중요한 것이다. 이는 자조모임을 지 원하는 프로그램이나 공간 등을 제공하는 기관(건강가정.다문 화가족지원센터, 육아종합지원센터 등)에서 자조모임 관련 사 업에 대한 효과성을 검증하는데 있어 단순한 기관의 모임 운영 에 대한 만족이나 참여 자체에 대한 만족이 중요한 것이 아니라 실질적인 양육 효과를 살펴보는 것이 중요하다는 것을 시사한 다. 공적 영역의 기관에서 영유아기 부모 대상사업으로 추진하 고 있는 자조모임에 대한 사업 평가를 함에 있어 실질적 양육에 기여하고 있는지에 대한 고려가 필요한 것이다.

최근 정부와 지자체의 정책적 지원과 부모들의 적극적인 호 응에 힘입어 육아종합지원센터와 건강가정.다문화가족지원센 터의 부모 자조모임은 지속적으로 활성화되고, 확대되고 있는 추세이다(N.-Y. Lee, 2017; T.-Y. Kim. 2020). 현재 센터에서 지원 하는 이러한 부모 자조모임이나 육아품앗이를 관리하기 위해 원활한 운영과 참여만족도를 평가의 기준으로 사용하는 경우 가 대부분이다. 그러나 본 연구의 결과를 고려할 때, 모임 참여 자들에게 지속적이고 적극적인 참여 동기를 부여하기 위해서 는 단순한 운영 수준, 참여만족도 측정으로는 부족함을 알 수
있다. 본 연구에서는 자조모임 운영이 잘 되는지 여부와 관계없 이, 실질적으로 내가 모임에서 어떤 긍정적 효과, 부정적 효과 를 얻었는지가 영유아 부모의 효능감 향상 및 양육스트레스 감 소를 이끌어냄을 밝혔다. 따라서 현재 시행되고 있는 모임 운영 위주의 관리, 평가에서 벗어나 참여자가 체감하는 긍정적/부정 적 효과를 측정하는 관리, 평가 방식이 도입될 필요성이 있다.

둘째, 영유아 부모의 자조모임에 대한 인식과 참여 효과는 부모의 연령과 수입에 따라 달라진다. 이는 성인 대상 상담/교 육 프로그램의 효과가 참여자의 개인적 특성에 따라 달라진 다는 선행연구(Y.-N. Ko \& Lee, M.-W, 2011; J.-Y. Ding \& Chi, 2017)와 일치하는 결과이다. 특히 높은 연령대의 부모가 자조 모임에 대해 더욱 긍정적인 태도를 가지고 있으며, 수입이 높 을수록 자조모임의 긍정적 효과를 높게 평가한다는 것을 고려 할 때, 다양한 계층의 부모의 특성을 고려한 폭넓은 자조모임 이 기획되고 운영될 필요가 있음을 알 수 있다. 또한, 본 연구 에서 부모의 자조모임 참여를 통해 변화시키고자 했던 주요변 인인 부모의 양육효능감과 양육스트레스는, 선행연구를 통해 연령과 소득에 따라 차이가 있는 것이 밝혀진 바(M.-J. Lee \& Kim, 2007; S.-H. Son \& Han, 2016), 서로 다른 수준의 효능감 과 스트레스를 받고 있는 집단을 별도로 묶어 모임을 구성했을 때 자조모임의 영향이 더욱 효과적으로 나타날 것으로 예상할 수 있다. 지금까지 저소득, 다문화, 한부모가정 등 네트워크가 필요한 집단에 집중되어 있던 부모 자조모임을 영유아 자녀를 둔 모든 부모들에게 확대하고 다양한 양육자 특성을 반영한 자조모임을 운영함으로써, 이후에는 육아에 있어 도움이 필요 한 많은 부모들에게 실질적인 도움을 제공할 수 있을 것이다.

최근 온라인 커뮤니티 등을 통해 비공식적인 자조모임들이 이루어지고 있으며, 공적영역에서 추진하고 있는 품앗이 사 업과 같은 자조모임 사업 확대를 위해서는 다양한 대상으로 의 확대는 필요할 것으로 생각된다. 특히, 공적영역이면서 전 문가의 지원이 가능한 건강가정.다문화가족지원센터 및 육아 종합지원센터 등에서 지원하는 자조모임은 일상적인 양육에 서 어려움을 경험하는 부모들에게 양육 부담을 완화하는 효과 적 완충제 역할을 할 수 있을 것이다. 최근 육아종합지원센터 에서는 단순한 양육기술 교육 외에 부모의 취미나 여가생활을 중심으로 한 소모임, 자녀와의 신체놀이, 야외놀이 활동 등을 진행하고 있다. 또한 건강가정.다문화가족지원센터에서도 육 아품앗이 프로그램을 중심으로 부모들의 재능기부를 통해 다 양한 주제의 활동을 시행하면서 기존의 일괄적인 육아모임에 서 탈피하고자 노력하고 있다. 이러한 경향은 부모의 다양한 성향과 요구를 만족시키고, 자조모임에의 자발적 참여를 증진 
시키는 데에 도움이 되리라 예상된다.

본 연구는 영유아 부모의 자조모임 참여를 통한 양육스트 레스 감소 효과를 높이기 위한 요인들을 분석하고, 이후 부모 자조모임 기획과 운영을 위한 기초자료를 제공하고자 하는 목 적으로 이루어졌다. 본 연구는 경기도 거주 영유아의 부모만 을 대상으로 진행된 조사이며, 코로나19로 인해 비대면 온라 인 설문조사로 이루어졌기 때문에, 결과를 전국의 모든 부모 에게 일반화시키는 데에 제한이 있을 수 있다. 그럼에도 불구 하고 본 연구는, 부모들이 자조모임을 통해 보다 큰 효과를 얻 기 위해서는 자조모임의 운영 자체보다 자조모임을 통해 참여 자가 얻은 긍정적/부정적 효과라는 실질적 결과가 더 중요함 을 밝힘으로써, 이후 자조모임 기획과 운영, 평가에 있어 중요 한 단서를 제공했다는 의의를 갖는다.

\section{Conflict of Interest}

No potential conflict of interest relevant to this article was reported.

\section{References}

\section{In English}

Abidin, R. R. (1990). Introduction to the special issue: The stresses of parenting. Journal of Clinical Child Psychology, 19(4), 298-301. doi:10.1207/s15374424jccp1904_1

Assel, M. A., Landry, S. H., Swank, P. R., Steelman, L., MillerLoncar, C., \& Smith, K. E. (2002). How do mothers' childrearing histories, stress and parenting affect children's behavioural outcomes? Child: Care, Health and Development, 28(5), 359-368. doi:10.1046/j.1365-2214.2002.00285.x

Bandura, A. (1989). Regulation of cognitive processes through perceived self-efficacy. Developmental Psychology, 25(5), 729-735. doi:10.1037//0012-1649.25.5.729

Deater-Deckard, K. (1998). Parenting stress and child adjustment: Some old hypotheses and new questions. Clinical Psychology: Science and Practice, 5(3), 314-332. doi:10.1111/j.14682850.1998.tb00152.x

Guralnick, M. J., Neville, B., Connor, R. T., \& Hammond, M. A. (2003). Family factors associated with the peer social competence of young children with mild delays. American Journal on Mental Retardation, 108(4), 272-287. doi:10.1352/08958017(2003)108<272:FFAWTP>2.0.CO;2

Jackson, A. P., \& Huang, C. C. (2000). Parenting stress and behavior among single mothers of preschoolers: The mediating role of self-efficacy. Journal of Social Service Research, 26(4), 29-42. doi:10.1080/01488370009511335

Jones, T. L., \& Prinz, R. J. (2005). Potential roles of parental self-efficacy in parent and child adjustment: A review. Clinical Psychology Review, 25(3), 341-363. doi:10.1016/ j.cpr.2004.12.004

Lavee, Y., Sharlin, S., \& Katz, R. (1996). The effect of parenting stress on marital quality: An integrated mother-father model. Journal of Family Issues, 17(1), 114-135. doi:10.1177/ 019251396017001007

Mäntymaa, M., Puura, K., Luoma, I., Latva, R., Salmelin, R. K., $\&$ Tamminen, T. (2012). Predicting internalizing and externalizing problems at five years by child and parental factors in infancy and toddlerhood. Child Psychiatry and Human Development, 43, 153-170. doi:10.1007/s10578011-0255-0

McCabe, H. (2008). The importance of parent support among families of children with autism in the people's republic of China. International Journal of Disability, Development and Education, 55(4), 303-314. doi:10.1080/10349120802489471

Mueller, T, G., Milian, M., \& Lopez, M, I., (2009). Latina mother's views of a parent-to-parent support group in the special education system. Research \& Practice for Persons with Severe Disabilities, 34(3-4), 1-10. doi:10.2511/ rpsd.34.3-4.113

Oddi, K. B., Murdock, K. W. Vadnais, S., Bridgett, D. J., \& Gartstein, M. A. (2013). Maternal and infant temperament characteristics as contributors to parenting stress in the first year postpartum. Infant and Child Development, 22(6), 553579. doi:10.1002/icd.1813

Thoits, P. A, (2011). Mechanisms linking social ties and support to physical and mental health. Journal of Health Social Behavior. 52, 145-161. doi:10.1177/0022146510395592

Yalom, I. (1985). The theory and practice of group psychotherapy through the group process. New York: Basic Books.

\section{In Korean}

Choi, E.-J. (2013). A study on the effects of participationin bookstart pumasi rearing communities on infant's gardians' social support and parenting self-efficacy(Master's thesis, Sungkyunkwan University, Seoul, Korea). Retrieved from http://www.riss. $\mathrm{kr} /$ link? id=T13246857

Choi, H.-S., \& Chung, O.-B. (2001). The development of an inventory for measuring the parenting self-efficacy of Korean mothers. Korean Journal of Child Studies, 22(3), 1-15.

Ding, J.-Y., \& Chin, M.-J. (2017, October). Effect of foreign spouses' experiences of social discrimination on depression - Mediation effect of participation in self-help groups-. 
Proceeding of the 2017 Annual Conference of Korean Association of Family Relations (pp. 210-210), Seoul, Korea.

Hwang, H.-M. (2017). Relationship between self-help group activity of parents with disabled children and parenting stress and parent efficacy (Master's thesis, Korea National Open University, Seoul, Korea). Retrieved from http://www.riss. $\mathrm{kr} / \mathrm{link}$ ?id=T14579425

Kim, S.-H. (2021). A study on the stress of young children's parents in COVID-19 pandemic - Focusing on COVID-19 stress and parenting stress. Korean Journal of Safety Culture. 13, 375-390. doi:10.52902/kjsc.2021.13.375

Kim, T.-Y. (2020). A study on the measures to activate self-help groups to strengthen the parental competency. Gyeonggido Family \& Women Research Institute. (Report No. 2020-05). Retrieved from Gyeonggido Women \& Family Foundation: https:// gwff.kr/rnd/report/statistics/?mod

Kim, T.-Y., Jung, H.-S., \& Yi, S.-H. (2016). Development and evaluation of a literacy program for multicultural family children. Family and Environmental Research, 54(1), 1-11.

Kim, Y.-R., \& Park, J.-Y. (2010). The effects of a poomassi parent self-help activity among parents of children with disabilities on parenting stress, family empowerment and family quality of life. Korean Journal of Special Education, 44(4), 445-465.

Ko, Y.-N., \& Lee, M.-W. (2011). A meta-analysis on the effectiveness of group bibliotherapy. Korean Journal of Counseling, 12(2), 489-504. doi:10.15703/kjc.12.2. 201104.489

Lee, I.-H., Choi, S.-Y., \& Song, H.-W. (2013). The structural relationship among mother's parenting stress, parenting efficacy, parenting behavior and children's social competence. The Journal of Child Education, 22(1), 69-81.

Lee, M.-J., \& Kim, Y.-M. (2007). A comparative study of parental competency, parenting practices, and social support between late and young parents. The Korea Association of Child Care and Education, (49), 289-309.

Lee, N.-Y. (2017). A study on the manuals and development direction of Gyeonggi child rearing sharing places. Gyeonggido Family \& Women Research Institute. (Report No. 2017-19). Retrieved from Gyeonggido Women \& Family Foundation: https:// gwff.kr/rnd/report/statistics/?mod

Lee, Y., \& Hwang, S. (2013). Effect of parenting stress control and quality of family life improvement through participation in leisure self-help group program. The Journal of Special Children Education, 15(1), 293-314.

Lee, Y. K. \& Kim, E. J. (2016). Becoming parents through 'Pumasi child rearing'. The Journal of Eco Early Childhood Education \& Care, 15(3), 33-53.

Lim, N.-Y. (2014). Reciprocal mothering: A case study of the Pumasi child rearing community forest-playground S(Master's thesis, Yonsei University, Seoul, Korea). Retrieved from http://
www.riss.kr/link?id=T13599225

Ministry of gender equality and family (2020). 2020 Family welfare business information. Seoul: Ministry of gender equality and family.

Ministry of health and welfare (2017). Announcement of the $3 \mathrm{rd}$ Mid-to-Long-Term Childcare Basic Plan (2018-2022) for 'Strengthening Social Responsibility for Childcare'. Seoul: Ministry of health and welfare.

Park, J.-Y., Cho, Y.-K., \& Kim, M.-S. (2004). A qualitative inquiry on the characteristics and support needs of children with emotional and behavioral issues in general classrooms. Journal of Emotional \& Behavioral Disorders, 20(2), 251-284.

Seo, C.-H., Park, J.-Y., Baek, M.-J., \& Kim, M.-S. (2017). Experience of 'overcoming the pain of family loss of suicide' through suicide bereavement support group: SPACE experiential model of family survivors. Journal of Family Relations, 22(3), 73-101.

Seo, S.-J., Kim, H.-J., \& Kim, S.-K. (2019). Stress and maternal parenting efficacy: Mediating and moderating effects of maternal satisfaction about their use of child care centers. Journal of Children's Literature and Education, 20(3), 361386. doi:10.22154/JCLE.20.3.14

Seo, T.-S., \& Lee, Y.-J. (2017). Research on experiences of elementary school children's education through self-help group of Korean migrant women's. The Journal of LearnerCentered Curriculum and Instruction, 17(24), 369-391.

Shin, S.-J. (1997). Effects of stress, social support and efficacy on mother's parenting behavior(Doctoral dissertation). Retrieved from http://www.riss.kr/link?id=T3628454

Son, S.-H., \& Han, C.-K. (2016). Parenting stress and household income: Focusing on the mediating effects of parents' selfefficacy and multi-group analysis on mothers and fathers. Korean Journal of Child Care and Education Policy, 10(3), 117-141.

Yang, Y.-J., \& Doh, H.-S. (2019). Pathways from marital conflict, coparenting, and parenting stress to mothers' parenting efficacy. Korean Journal of Child Studies, 40(3), 39-51.

\section{ORCID}

Tae-Yeon Kim http://orcid.org/0000-0001-9721-6358

Na-Yeon Lee http://orcid.org/0000-0003-3191-2478

Received October 29, 2021

Revision received November 26, 2021

Accepted December 10, 2021 